\title{
Ab Initio Thermodynamics Reveals the Nanocomposite Structure of Ferrihydrite
}

\section{Michel Sassi ( $\square$ michel.sassi@pnnl.gov)}

Pacific Northwest National Laboratory

\section{Anne Chaka}

Pacific Northwest National Laboratory

\section{Kevin Rosso}

Pacific Northwest National Laboratory https://orcid.org/0000-0002-8474-7720

\section{Article}

Keywords: Ferrihydrite, thermodynamics

Posted Date: May 11th, 2021

DOI: https://doi.org/10.21203/rs.3.rs-496341/v1

License: (c) (1) This work is licensed under a Creative Commons Attribution 4.0 International License.

Read Full License

Version of Record: A version of this preprint was published at Communications Chemistry on September 20th, 2021. See the published version at https://doi.org/10.1038/s42004-021-00562-7. 


\title{
Ab Initio Thermodynamics Reveals the Nanocomposite Structure of Ferrihydrite
}

\author{
Michel Sassi ${ }^{1,}{ }^{*}$, Anne M. Chaka ${ }^{1}$, and Kevin M. Rosso ${ }^{1}$ \\ ${ }^{1}$ Physical and Computational Sciences Directorate, Pacific Northwest National Laboratory, Richland, \\ Washington 99354, USA
}

\begin{abstract}
:
Ferrihydrite is a poorly crystalline iron oxyhydroxide nanomineral that serves a critical role as the most bioavailable form of ferric iron for living systems. However, its atomic structure and composition remain unclear due in part to ambiguities in interpretation of X-ray scattering results. Prevailing models so far have not considered the prospect that at the level of individual nanoparticles multiple $X$-ray indistinguishable phases could coexist. Using ab initio thermodynamics we show that ferrihydrite is likely a nanocomposite of distinct structure types whose distribution depends on particle size, temperature, and hydration. Nanoparticles of two contrasting single-phase ferrihydrite models of Michel and Manceau are here shown to be thermodynamically equivalent across a wide range of temperature and pressure conditions despite differences in their structural water content. Higher temperature and water pressure favor the formation of the former, while lower temperature and water pressure favor the latter. For aqueous suspensions at ambient conditions, their coexistence is maximal for particle sizes up to $12 \mathrm{~nm}$. The predictions can be connected to and help resolve different observations in various experiments.
\end{abstract}




\section{Introduction:}

Ferrihydrite is one of the most important, abundant, and enigmatic minerals of the iron(oxyhydr)oxide family. Typically the first product of Fe(III) hydrolysis or rapid oxidation of aqueous Fe(II), this poorly crystalline nanomineral of 2-10 $\mathrm{nm}$ grain size can be found across a diversity of soil and aquatic environments on Earth. ${ }^{1}$ In industry, its high reactive surface area and cost-effectiveness make it a potent sorbent for water purification ${ }^{2}$ and catalysis. ${ }^{3}$ However, as a poorly ordered material it has remained difficult for X-ray diffraction (XRD) and scattering techniques to precisely determine its structure, beyond providing an indication of major ferrihydrite types distinguished by the number of peaks present in the XRD pattern. While so-called 2- and 6-line are the most common, ferrihydrite can also exhibit an intermediate numbers of peaks. ${ }^{1,4-6}$ For example, in Si-rich and high temperature conditions, synthetic and natural 7-line ferrihydrite have been characterized. ${ }^{4,7,8}$ Despite these XRDbased distinctions, $\mathrm{X}$-ray pair distribution function analyses suggest that there are no significant structural differences between 2- and 6-line ferrihydrite, and that the differences instead reflect the variations in the average size of the coherent scattering domains. ${ }^{6}$ This is tacitly consistent with the fact that ferrihydrite exists exclusively as 2-10 nm nanoparticles, mostly spherical in shape, with 2-line ferrihydrite possessing smaller particle sizes ( 1-4 $\mathrm{nm}$ ) and being the most hydrated. ${ }^{6,9-14}$

More than half a century of experimental research on its structure and composition has yet to produce a unanimously accepted model. ${ }^{1,15,16,10,17-23}$ A variety of structures have been proposed and remain the subject of ongoing scrutiny, including a single-phase, ${ }^{15,16,10,21}$ a mixture of defect-free and defective structural units, ${ }^{20,24}$ and hybrid model. ${ }^{25} \mathrm{~A}$ single-phase model entailing $20 \%$ tetrahedral iron here termed the Michel model ${ }^{15}$ was later questioned as a non-unique solution to X-ray data by comparing it to a different single-phase structure composed entirely of octahedral iron in the Manceau model. ${ }^{16}$ Whether or not tetrahedral iron is present ${ }^{22,23}$ remains an important but uncertain aspect with respect to unambiguous determination of the structure. This is further complicated by the likelihood that both the structure and properties of ferrihydrite (e.g., magnetism) depend on composition, particularly water content, and particle size..$^{9,14,26,27}$ The only well-accepted features of the various proposed structural models are that ferrihydrite has a hexagonal close packed anion lattice, is made of a mixture of defective and defect-free structural units, and has variable hydroxyl and water adsorption or incorporation. ${ }^{1,20,21}$

In this regard it is noteworthy that the structure and composition of ferrihydrite have not been studied systematically as a function of synthesis and storage conditions such as $\mathrm{pH}$ and temperature. The slow and spontaneous transformation of ferrihydrite to more stable iron (oxyhydr)oxides such as goethite and hematite are known to depend on both $\mathrm{pH}$ and temperature. ${ }^{28,29}$ The uncertainties about the structure also make it difficult for computational molecular modeling to rigorously encompass all but the most straightforward single-phase structure models. Consequently only a limited set of density functional theory (DFT) investigations have been performed to date, focused primarily on the singlephase Michel et al. model, ${ }^{15}$ examining its virtual bulk lattice thermodynamics ${ }^{30,31}$ and the role of hydration on structural stability and magnetic properties. ${ }^{27}$ The collective observations leave open the 
possibility that at the nanoscale ferrihydrite is actually an assemblage of coexisting X-ray indistinguishable particles, the distribution of which depends on environmental conditions during formation and that may subsequently evolve over time.

The present study investigates this prospect using density functional theory (DFT) calculations adjusted for chemical potentials in aqueous suspension at ambient conditions and taking into account particle surface free energies. The fact that ferrihydrite exists only in nanoparticle form clearly indicates the importance of its surfaces for stabilization. Studies that have examined its size-dependent properties $^{13,14}$ as well as its hypothetical surface structure, reactivity, and surface Gibbs free energies ${ }^{26,32-35}$ suggest that ferrihydrite nanoparticles can be described as having a defect-free, low hydroxyl core consisting of the single-phase model of Michel $\left(\mathrm{Fe}_{5} \mathrm{O}_{8} \mathrm{H}\right)^{15}$ and a more hydrated (i.e., $\mathrm{Fe}_{5} \mathrm{O}_{8} \mathrm{H}+n \mathrm{H}_{2} \mathrm{O}$ ) iron-deficient crystallographically-oriented surface region depleted in Fe2 octahedral and Fe3 tetrahedral sites. Using this model, estimation of the Gibbs free energy as a function of the particle size at $298 \mathrm{~K}$ and 1 bar indicated that ferrihydrite up to $8 \mathrm{~nm}$ in particle size should be stable with respect to hematite. ${ }^{35}$ This structural description recently showed good recovery of the sizedependent distribution and density of hydroxyl groups at the surface, ${ }^{36}$ though it is unclear the extent to which such a finding should be diagnostic for structure.

By combining similar thermodynamic concepts with DFT calculated energetics in an ab initio thermodynamics (AIT) approach, here we show that ferrihydrite can be described as a nanocomposite of the single-phase models of Michel $^{15}$ and Manceau ${ }^{16}$ that evolves as a function of particle size, temperature, $\mathrm{pH}$, and the partial pressure of water. We show how their relative stabilities evolve in terms of system conditions and increasing particle size that ultimately ends in their conversion to more stable crystalline bulk phases of hematite $\left(\alpha-\mathrm{Fe}_{2} \mathrm{O}_{3}\right)$, goethite $(\alpha-\mathrm{FeOOH})$ and lepidocrocite $(\gamma-\mathrm{FeOOH})$. We include in the comparison an orthorhombic phase similar to goethite but with the $\mathrm{Fe}_{5} \mathrm{O}_{8} \mathrm{H}$ stoichiometry that was predicted to have a low-energy topology competitive with the Michel model though remaining structurally incompatible with the XRD and PDF data of ferrihydrite. ${ }^{27}$ We also show how the nanocomposite description connects in specific ways to key aspects of experimental observations. The findings strongly suggest that the ongoing debate about the structure of ferrihydrite can be resolved with closer examination of sample-specific differences.

\section{Results and Discussion:}

Relative phase stability of bulk lattices. We first considered virtual bulk structure types of ferrihydrite, taking the single-phase models of Michel ${ }^{15}$ and Manceau, ${ }^{16}$ for direct energetic comparison with various Fe(III)-(oxyhydr)oxide phases whose relative stabilities are well known. Following the methodology described in Ref[37], we performed DFT-based AIT calculations to predict as function of temperature and the chemical potential of water the relative phase stabilities of hematite, goethite, lepidocrocite, the two single-phase ferrihydrite models and the hypothetical orthorhombic phase of Sassi and Rosso. ${ }^{27}$ To first establish the accuracy of the approach we examined standard conditions of $P=1$ bar. The chemical potential, $\mu$, of each mineral phase, $i$, was determined by the following equation: 


$$
\mu_{i}(T, P)=\mathrm{E}_{i}^{\mathrm{Tot}, \mathrm{OK}}+\mathrm{E}_{i}^{\mathrm{ZPE}}+\Delta \mu_{i}(T, P)
$$

where $E_{i}^{\text {Tot, } 0 \mathrm{~K}}$ is the DFT total energy at $0 \mathrm{~K}, \mathrm{E}_{i}^{\mathrm{ZPE}}$ is the zero point energy and $\Delta \mu_{i}(T, P)$ the correction to the chemical potential for temperature, $T$, and pressure $P$. In the case of hematite, here taken as the reference mineral phase, the $\mathrm{DFT}+\mathrm{U}$ calculated values of $\Delta \mu(T, P)$, at $\mathrm{P}=1$ bar are in very good agreement, within $3 \mathrm{~kJ} / \mathrm{mol}^{-} \mathrm{Fe}_{2} \mathrm{O}_{3}$, with experiment ${ }^{38}$ as shown in Figure 1.

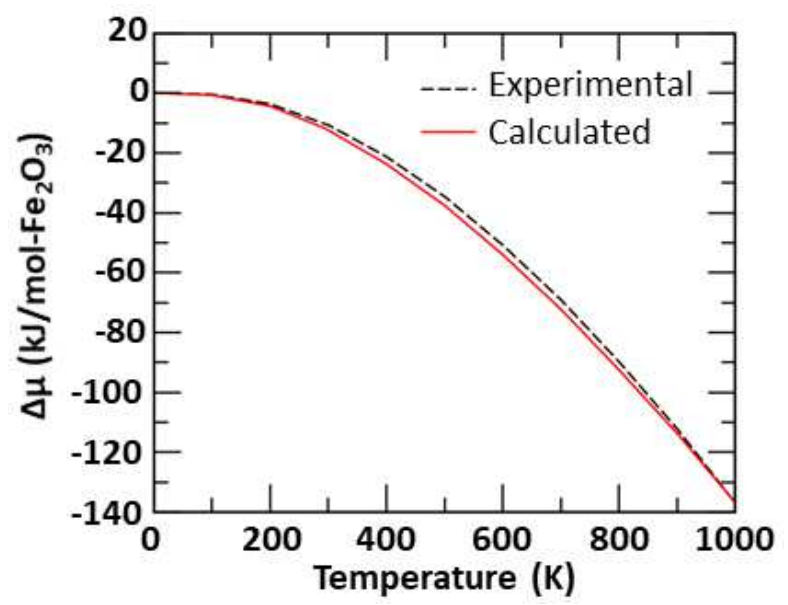

Figure 1: Evolution of the chemical potential with temperature. Comparison between $D F T+U$ calculated and experimental JANAF values of $\Delta \mu(T, P)$ (in $\mathrm{kJ} / \mathrm{mol}^{-}-\mathrm{Fe}_{2} \mathrm{O}_{3}$ ) for hematite $\left(\alpha-\mathrm{Fe}_{2} \mathrm{O}_{3}\right)$ at $\mathrm{P}=1$ bar.

Depending on the stoichiometry of each mineral phase, the Gibbs free energy at standard (T,P) conditions, $\Delta G^{\circ}(T, P)$, expressed in $\mathrm{kJ} / \mathrm{mol}^{-}-\mathrm{FeO}_{3 / 2}$, was calculated for reactions (2) and (3) according to relationships (4) and (5) respectively, in which each $\mu_{i}$ was calculated as defined by equation (1):

$$
\begin{gathered}
2 \mathrm{FeOOH} \rightarrow \alpha-\mathrm{Fe}_{2} \mathrm{O}_{3}+\mathrm{H}_{2} \mathrm{O} \\
2 \mathrm{Fe}_{5} \mathrm{O}_{8} \mathrm{H} \rightarrow 5\left[\alpha-\mathrm{Fe}_{2} \mathrm{O}_{3}\right]+\mathrm{H}_{2} \mathrm{O} \\
\Delta G^{\circ}(T, P)=\mu_{\mathrm{FeOOH}}(T, P)-\frac{1}{2}\left[\mu_{\alpha-\mathrm{Fe}_{2} \mathrm{O}_{3}}(T, P)+\mu_{\mathrm{H}_{2} \mathrm{O}}(T, P)\right] \\
\Delta G^{\circ}(T, P)=\frac{1}{5} \mu_{\mathrm{Fe}_{5} \mathrm{O}_{8} \mathrm{H}}(T, P)-\frac{1}{2} \mu_{\alpha-\mathrm{Fe}_{2} \mathrm{O}_{3}}(T, P)-\frac{1}{10} \mu_{\mathrm{H}_{2} \mathrm{O}}(T, P)
\end{gathered}
$$

At standard conditions ( $\mathrm{T}=298.15 \mathrm{~K}$ and $\mathrm{P}=\mathrm{pH}_{2} \mathrm{O}=1$ bar) the value of $\Delta \mathrm{G}^{\circ}$ obtained for equations (4) and (5) for hematite, goethite, lepidocrocite, the two ferrihydrite models, and the orthorhombic phase are shown in Table 1. As in previous ${ }^{30}$ theoretical calculations of $\Delta G^{\circ}$ between bulk hematite and goethite, our value of the Gibbs free energy at these (T,P) conditions predicts that goethite should be slightly more energetically favorable than hematite. While inconsistent with the assertion from experiments, ${ }^{14,39}$ the absolute error of the calculated $\Delta G^{\circ}$ remains small, about $3 \mathrm{~kJ} / \mathrm{mol}$ $\mathrm{FeO}_{3 / 2}$. Furthermore, if we consider instead the partial pressure of water in equilibrium with liquid water at ambient conditions ( $\mathrm{T}=298.15 \mathrm{~K}$ and $p \mathrm{H}_{2} \mathrm{O}=32 \mathrm{mbar}$ ), we now find that goethite is slightly less 
favorable than hematite by about $0.9 \mathrm{~kJ} / \mathrm{mol}^{-\mathrm{FeO}_{3 / 2}}$ in good agreement with experiments. ${ }^{14,39}$ The calculated Gibbs free energy of lepidocrocite, relative to hematite, is close to the experimental value for both partial pressures of water.

For the Michel ferrihydrite model, our calculated Gibbs free energies are in good agreement with previous DFT calculations. ${ }^{30}$ However, all such calculations are not readily compared to experiments because they do not take into account the energy cost associated with the surface energy of ferrihydrite nanoparticles. ${ }^{30}$ We also note that the experimentally determined $\Delta G^{\circ}$ values were calculated using the assumption that ferrihydrite has the stoichiometry $\mathrm{Fe}(\mathrm{OH})_{3}$, which is not the case for the Michel $\left(\mathrm{Fe}_{5} \mathrm{O}_{8} \mathrm{H}\right)$ and $\mathrm{Manceau}(\mathrm{FeOOH})$ models being considered here. Use of the highly hydrous formula $\mathrm{Fe}(\mathrm{OH})_{3}$ in the literature stems from the difficulty to precisely distinguish structural versus physisorbed water in experimental characterization studies. As shown in Table 1, the comparison of $\Delta G^{\circ}$ values obtained at $\mathrm{T}=298.15 \mathrm{~K}$ and $p \mathrm{H}_{2} \mathrm{O}=1$ bar for the Manceau and Michel models suggests that

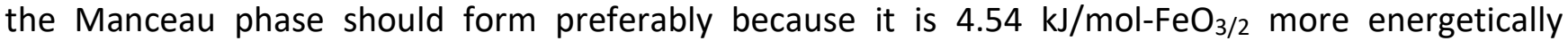
favorable than the Michel model, at least in the hypothetical bulk crystal structure form. For $p \mathrm{H}_{2} \mathrm{O}=32$ mbar, the Manceau model is still more favorable than the Michel model but the energetic difference is

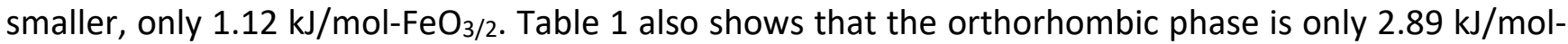
$\mathrm{FeO}_{3 / 2}$ less favorable than the Michel model at both $\mathrm{pH}_{2} \mathrm{O}$.

\begin{tabular}{|c|c|c|c|c|}
\hline Structure & $\begin{array}{c}\Delta G_{\mathrm{GGA}+\mathrm{U}}^{\circ} \\
p \mathrm{H}_{2} \mathrm{O}=1 \text { bar }\end{array}$ & $\begin{array}{c}\Delta G_{\mathrm{GGA}+\mathrm{U}} \\
\mathrm{pH}_{2} \mathrm{O}=32 \mathrm{mbar}\end{array}$ & $\Delta \boldsymbol{G}_{\mathrm{GGA}+\mathrm{U}^{30}}^{\circ}$ & $\Delta G_{\operatorname{Exp}}^{\circ} 14,39$ \\
\hline Hematite $\left(\alpha-\mathrm{Fe}_{2} \mathrm{O}_{3}\right)$ & 0.00 & 0.00 & 0.00 & $0.00 \pm 0.60$ \\
\hline Goethite $(\alpha-\mathrm{FeOOH})$ & -3.34 & 0.93 & -1.50 & $0.16 \pm 0.80$ \\
\hline Lepidocrocite ( $\gamma$-FeOOH) & 7.22 & 11.49 & 10.20 & $8.06 \pm 2.40$ \\
\hline Manceau Model (FeOOH) & 0.09 & 4.36 & $\mathrm{n} / \mathrm{a}$ & $16.90-22.70 \pm 1.20$ \\
\hline Michel Model $\left(\mathrm{Fe}_{5} \mathrm{O}_{8} \mathrm{H}\right)$ & 4.63 & 5.48 & 6.90 & $16.90-22.70 \pm 1.20$ \\
\hline Orthorhombic $\left(\mathrm{Fe}_{5} \mathrm{O}_{8} \mathrm{H}\right)$ & 7.52 & 8.37 & $\mathrm{n} / \mathrm{a}$ & $\mathrm{n} / \mathrm{a}$ \\
\hline
\end{tabular}

Table 1: Gibbs free energies of bulk mineral phases. Calculated Gibbs free energies (in kJ/mol-FeO ${ }_{3 / 2}$ ) with respect to $1 / 2\left[\alpha-\mathrm{Fe}_{2} \mathrm{O}_{3}\right]$ at $\mathrm{T}=298.15 \mathrm{~K}$ and two water partial pressures $\left(p \mathrm{H}_{2} \mathrm{O}\right)$.

To examine the role of water chemical potential on relative phase stabilities, we calculated $\Delta G$ over a broad range of hypothetical temperature $(0 \mathrm{~K}-1000 \mathrm{~K})$ and water partial pressure $\left(10^{-6} \mathrm{mbar}-\right.$

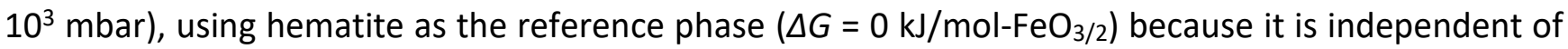
the water chemical potential (i.e., $\mathrm{OH} / \mathrm{Fe}=0$ ). As shown in Figure 2a, compared to hematite the next most "dry" phases are the Michel ferrihydrite model and the orthorhombic phase, both of which possess the same $\mathrm{Fe}_{5} \mathrm{O}_{8} \mathrm{H}$ stoichiometry. The Michel model is always less favorable than hematite, and the orthorhombic phase is always less favorable than the Michel model, with both following a very similar free energy planarity to hematite because of their low molar water contents of $\mathrm{OH} / \mathrm{Fe}=0.2$. At higher molar water contents of $\mathrm{OH} / \mathrm{Fe}=1.0$ are the phases goethite, lepidocrocite and the Manceau 
ferrihydrite model, each having the FeOOH stoichiometry and each following a similar planarity but with a much higher dependence on the chemical potential of water collectively. Regardless of the (T,P) conditions, our calculations predict that the Manceau model is less favorable than goethite, and lepidocrocite is always less favorable than the Manceau model.

Phase crossover regions among these three major groups of phases $(\mathrm{OH} / \mathrm{Fe}=0,0.2$, and 1.0) provide initial clues into the prospect of phase coexistence at select $(T, P)$ conditions. At the reference state of $p \mathrm{H}_{2} \mathrm{O}=1$ bar, the experimental temperature for the goethite-hematite phase transition is in the range of $340 \mathrm{~K}-370 \mathrm{~K}, 1,14$ which is satisfactorily reproduced by our calculated temperature of $340 \mathrm{~K}$ (Fig. 2b). At $\mathrm{T}=300 \mathrm{~K}$ and $p \mathrm{H}_{2} \mathrm{O}=1$ bar, the calculations predict that the Manceau ferrihydrite model is more stable than the Michel model, though they become thermodynamically isoenergetic at the mildly elevated $\mathrm{T}=360 \mathrm{~K}$. This suggests that the presence of tetrahedral iron in the core of ferrihydrite nanoparticles, as present in the single-phase Michel model, could be favored at mildly elevated temperature. In comparing the domains of stability for the Michel and Manceau ferrihydrite models, the results in Figure $2 \mathrm{~b}$ reinforce a picture that the Michel model could comprise a relatively dry polymorph of ferrihydrite, while the Manceau model could comprise a wetter polymorph, with temperature as an important determining variable within a few degrees. 

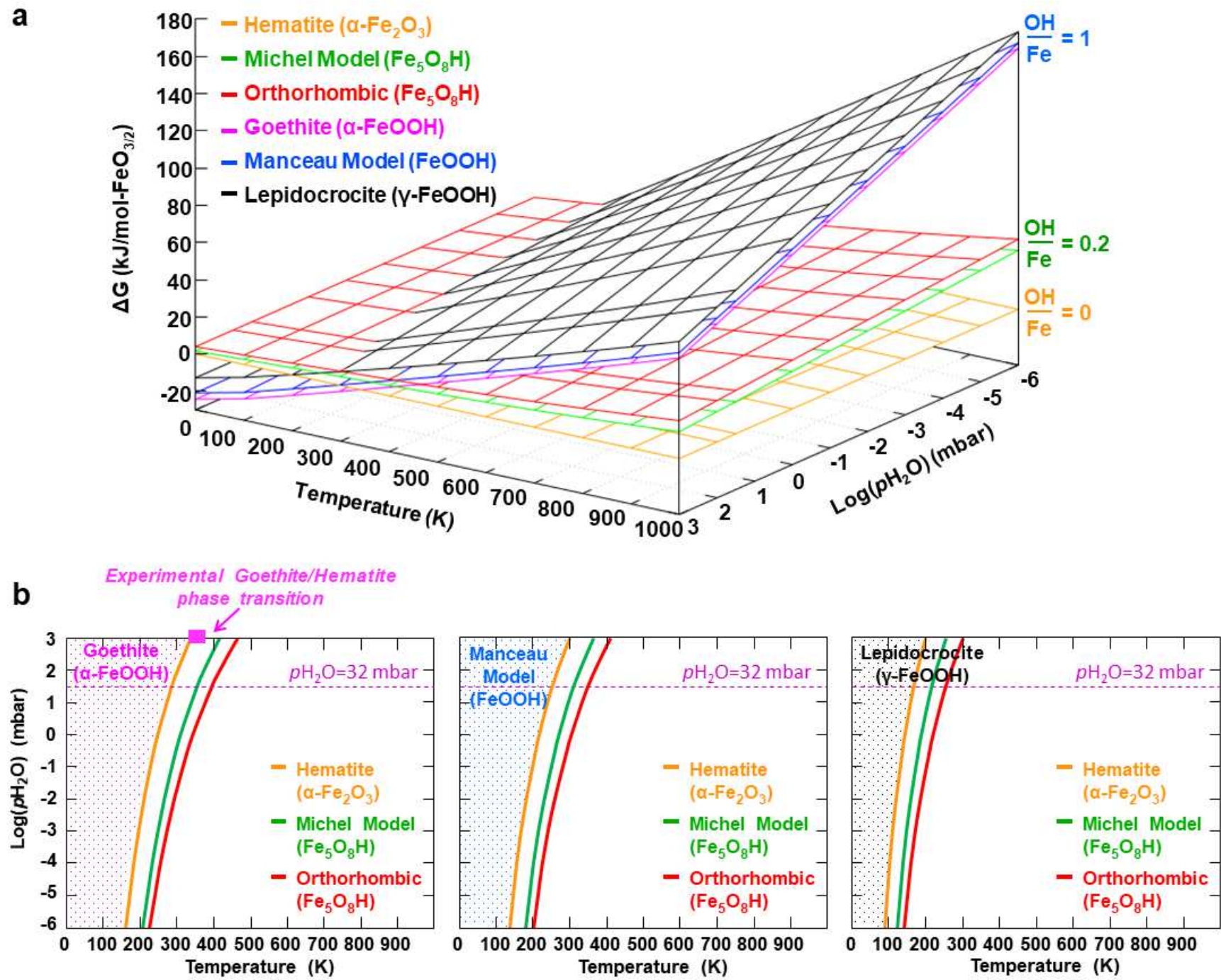

Figure 2: Relative phase stability of mineral phases. Calculated relative bulk phase stabilities for hematite, goethite, lepidocrocite, the two ferrihydrite models and the orthorhombic structure. a) 3D plot of the Gibbs free energy as function of the temperature and water partial pressure. b) Water pressure-temperature phase diagrams showing the domain of stability for each phase and the conditions at various phase boundaries. The purple dashed line indicates the water pressure for which $p \mathrm{H}_{2} \mathrm{O}=32$ mbar. The color dotted areas highlight the $(T, P)$ conditions at which each FeOOH phase is the most thermodynamically favorable.

Nanoparticle thermodynamics and coexistence. Because of the clear importance of including surface free energy contributions towards understanding relative phase stabilities at the nanoscale, we extended the AIT calculations to consider the effects of finite particle size. The estimation of the surface energy contribution at finite particle size requires the explicit calculation of the surface entropy and enthalpy. As shown in Figure S2 in Supplementary Materials, using classical molecular mechanics and explicitly described atomistic surface terminations we calculated a weighted averaged hydroxylated

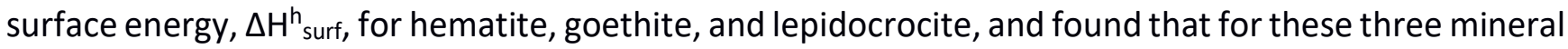
phases $\Delta \mathrm{H}^{\mathrm{h}}$ surf is $0.75 \mathrm{~J} / \mathrm{m}^{2}, 0.55 \mathrm{~J} / \mathrm{m}^{2}$, and $0.44 \mathrm{~J} / \mathrm{m}^{2}$, respectively. These $\Delta \mathrm{H}^{\mathrm{h}}$ surf values are in very good agreement with the experimentally determined surface energy of hematite $\left(0.75 \mathrm{~J} / \mathrm{m}^{2}\right)$, goethite $(0.60$ 
$\mathrm{J} / \mathrm{m}^{2}$ ) and lepidocrocite $\left(0.40 \mathrm{~J} / \mathrm{m}^{2}\right) \cdot{ }^{14}$ The calculated $\Delta \mathrm{H}^{\mathrm{h}}$ surf for the orthorhombic phase, $0.59 \mathrm{~J} / \mathrm{m}^{2}$, is very close to the one of goethite, which is not surprising given the fact that these two phases share similar structural features. ${ }^{27}$ In contrast to these well-ordered phases, performing the same kind of explicitly described surface calculations to determine the weighted averaged hydroxylated surface energies of the Manceau and Michel ferrihydrite models would be of questionable value due to expectedly important irregularities in particle shape, surface stoichiometry and reconstruction, and defects. For the ferrihydrite models we therefore instead rely on a range of reasonable surface energies, as discussed by Pinney et al. ${ }^{30}$ We assume a lowest surface energy value of $0.1 \mathrm{~J} / \mathrm{m}^{2}$, as determined by Hiemstra, ${ }^{35}$ and a highest surface energy of $0.4 \mathrm{~J} / \mathrm{m}^{2}$, the experimentally determined surface energy of lepidocrocite. ${ }^{14}$

Relative phase stabilities for the six mineral phases of interest as a function of particle size were computed for $\mathrm{pH}_{2} \mathrm{O}=32 \mathrm{mbar}$, and three different temperatures of $\mathrm{T}=100 \mathrm{~K}, 298.15 \mathrm{~K}$, and $500 \mathrm{~K}$, variation of which enables insight into the completeness of the overlapping stability fields for the two types of studied ferrihydrite nanoparticles (Fig. 3). A comparison between $p \mathrm{H}_{2} \mathrm{O}=32$ mbar and $p \mathrm{H}_{2} \mathrm{O}=1$ bar results is given in Figure S3. The curves with open squares are those obtained for ferrihydrite nanoparticles with a minimal surface energy of $0.1 \mathrm{~J} / \mathrm{m}^{2}$, while the curves with open circles are calculated using a surface energy of $0.4 \mathrm{~J} / \mathrm{m}^{2}$. In the following, ferrihydrite nanoparticles with a structure based on the Michel model will be referred as the Michel ferrihydrite nanoparticles and, likewise for those of the Manceau. Relative phases stabilities can now be discussed in terms of particle size dependency, over the evaluated size range of $\sim 0$ to $16 \mathrm{~nm}$ in diameter.

As shown in Figure 3a, at a temperature of $100 \mathrm{~K}$ the lowest energy phase is predicted to be Manceau ferrihydrite particles over the entire size range examined when assigned their lowest surface free energy $\left(0.1 \mathrm{~J} / \mathrm{m}^{2}\right)$. Manceau particles at their highest surface free energy $\left(0.4 \mathrm{~J} / \mathrm{m}^{2}\right)$ follow closely with goethite particles as the two next lowest free energy phases over most of the size range. This suggests that at this low temperature Manceau ferrihydrite nanoparticles would become unstable with respect to goethite when their diameter increases above the range from $6 \mathrm{~nm}$ to $16 \mathrm{~nm}$. At $100 \mathrm{~K}$, no ferrihydrite particles should be expected with a diameter above $16 \mathrm{~nm}$. Importantly, comparison between Michel and Manceau ferrihydrite nanoparticles suggests that the former could only be stable below $3.2 \mathrm{~nm}$ when assigned its lowest surface free energy, compared to the highest surface free energy Manceau phase. In this case, hypothetically, if chemical conditions were such that the exchange of one $\mathrm{Fe}^{3+}$ for three $\mathrm{H}^{+}$were possible at no energetic cost (i.e., to enable $\mathrm{FeO}_{5} \mathrm{H}_{8}+2 \mathrm{H}_{2} \mathrm{O}=\mathrm{FeOOH}$ ) then Michel ferrihydrite nanoparticles with diameters larger than $3.2 \mathrm{~nm}$ would transform into Manceau ferrihydrite nanoparticles instead of transforming into $3.6 \mathrm{~nm}$ goethite; the red hatched area in Figure $3 a$ highlights that at $100 \mathrm{~K}$ coexistence of the Manceau and Michel ferrihydrite nanoparticles is possible up to about $3.2 \mathrm{~nm}$ in size.

At room temperature, the coexistence field between Michel and Manceau ferrihydrite nanoparticles is predicted to be much larger and unconstrained by their surface energies, as shown in Figure 3b. At 298.15 K, the Manceau and Michel ferrihydrite nanoparticles are effectively isoenergetic 
up to particle diameters up to $\sim 5 \mathrm{~nm}$, after which these particles become increasingly unstable with respect to hematite. A destabilization sequence can be defined in terms of specific ferrihydrite phase and surface free energy. The highest surface free energy Manceau and Michel ferrihydrite nanoparticles would start to transform into hematite first, followed by the lowest surface free energy Michel particles at $>11.8 \mathrm{~nm}$, and ultimately the lowest surface free energy Manceau particles at diameters $>14 \mathrm{~nm}$. Here again, no ferrihydrite nanoparticles should be observable with diameters larger than $16 \mathrm{~nm}$, consistent with expectations. And for $\mathrm{pH}_{2} \mathrm{O}=1$ bar, the Michel ferrihydrite nanoparticles should be stable with respect to goethite up to $8 \mathrm{~nm}$ (Fig. S3e), in good agreement with the previous calculations of Hiemstra. ${ }^{35}$

From the large size of the coexistence field in Figure 3b, a major finding of our study is the likelihood of a structural diversity of ferrihydrite nanoparticles at room temperature in aqueous suspension, with at least two single-phase ferrihydrite structure types predicted to be energetically favorable simultaneously over a fairly large particle size distribution. Considering the ongoing debate across experimental studies about the structure of ferrihydrite, which in large part is based on the challenges in obtaining a unique structural signature of ferrihydrite based on X-ray diffraction and scattering analyses, this finding is particularly relevant.

Also at room temperature, we remark that the orthorhombic phase ${ }^{27}$ is predicted to behave very similarly to lepidocrocite across the whole range of particle size investigated. For $p \mathrm{H}_{2} \mathrm{O}=32 \mathrm{mbar}$, the orthorhombic phase is found to be energetically more favorable than lepidocrocite at all particle sizes investigated. Although there is no indication from experiments that such an orthorhombic phase exists, this finding would suggest that if it did exist it could be maintained at very low concentrations as the transient intermediate during transformation of Michel ferrihydrite particles to goethite. The prospect of this phase potentially mediating a solid-state transformation pathway will be explored in future modeling work.

At the highest evaluated temperature of $500 \mathrm{~K}$, the formation of hematite is preferred over goethite and the Michel ferrihydrite nanoparticles are generally more energetically favorable than the Manceau ferrihydrite nanoparticles (Fig. 3c). As indicated by what now again is a relatively small coexistence field similar to that at $100 \mathrm{~K}$, the two ferrihydrite structure types coexist over a small range of diameters, up $2.6 \mathrm{~nm}$, beyond which the Michel ferrihydrite nanoparticles should be the only ferrihydrite structure present. Similar to the case at $100 \mathrm{~K}$ but in the opposite sense, if iron and proton exchanges are possible then Manceau ferrihydrite nanoparticles with a diameter larger than $2.6 \mathrm{~nm}$ should be able to transform into Michel ferrihydrite nanoparticles prior to transformation into hematite. At $500 \mathrm{~K}$, Michel ferrihydrite nanoparticles should start to transform into hematite if their diameter is larger than $4.5 \mathrm{~nm}$ and no ferrihydrite should be observable for nanoparticles with diameter larger than $8.2 \mathrm{~nm}$. 

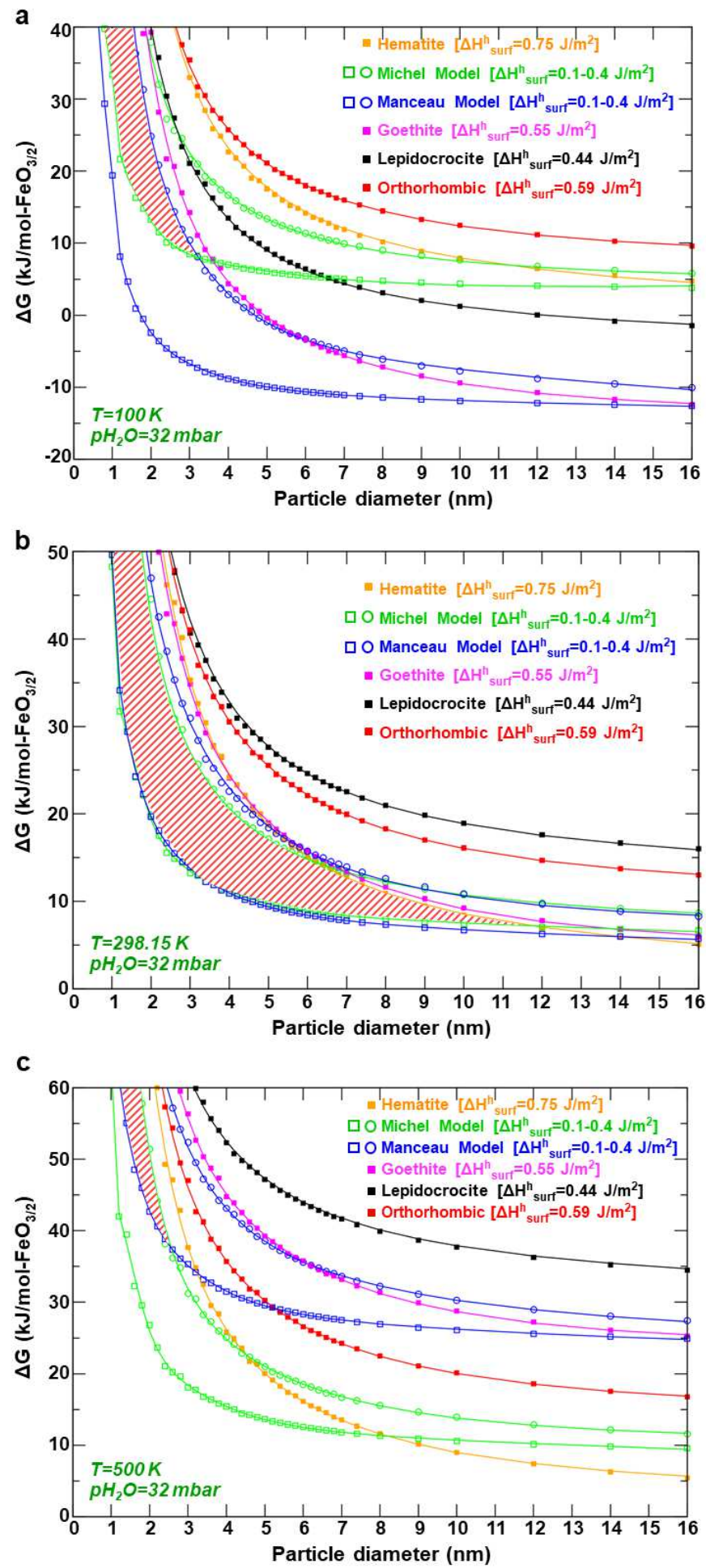

Figure 3: Coexistence of structurally different Fh nanoparticles. Particle-size dependency of the relative phase stability of the Manceau and Michel ferrihydrite models as well as for goethite, lepidocrocite, hematite and the orthorhombic phase for $\mathrm{pH}_{2} \mathrm{O}=32 \mathrm{mbar}$ and (a) $\mathrm{T}=100 \mathrm{~K}$, (b) $\mathrm{T}=298.15$ $\mathrm{K}$, and (c) $\mathrm{T}=500 \mathrm{~K}$. For the two ferrihydrite models, the curves with open squares were obtained using $\Delta \mathrm{H}_{\text {surf }}^{\mathrm{h}}=0.1 \mathrm{~J} / \mathrm{m}^{2}$, while the curves with open circles used $\Delta \mathrm{H}_{\text {surf }}^{\mathrm{h}}=0.4 \mathrm{~J} / \mathrm{m}^{2}$. Square filled curves used $\Delta \mathrm{H}^{\mathrm{h}}$ surf calculated for hydroxylated periodic surface crystals. The red hatched area represents the sizerange of particles for which the two ferrihydrite models can potentially coexist. 
Connection to experimental data. It is possible to connect our nanocomposite prediction to the hydrothermal aging experiment of Michel et al., ${ }^{13}$ who monitored the evolution of average particle size and composition as function of aging time during 14 hours at $175{ }^{\circ} \mathrm{C}$ (473 K) (see Table S2 and S3 in supplementary materials of Ref[13]). Starting from an initial ( $t=0$ hour) composition and average particle size of $\mathrm{Fe}_{8.2} \mathrm{O}_{15.9} \mathrm{H}_{7.4} \cdot 3 \mathrm{H}_{2} \mathrm{O}$ and $2.28 \mathrm{~nm}$, respectively, they observed a progressive decrease in water content and increase in average particle size over aging time ( $t=3$ hours: $\mathrm{Fe}_{8.6} \mathrm{O}_{16.1} \mathrm{H}_{6.2} \cdot 2.5 \mathrm{H}_{2} \mathrm{O}$ and $3.55 \mathrm{~nm} ; t=8$ hours: $\mathrm{Fe}_{10} \mathrm{O}_{16} \mathrm{H}_{2} \cdot 1.2 \mathrm{H}_{2} \mathrm{O}$ and $6.8 \mathrm{~nm} ; t=11$ hours: $\mathrm{Fe}_{10} \mathrm{O}_{16} \mathrm{H}_{2} \cdot 0.5 \mathrm{H}_{2} \mathrm{O}$ and $9.06 \mathrm{~nm}$ ). Ferrihydrite was the only phase observed from $t=0-7$ hours whereas from $t=7-12$ hours ferrihydrite and an increasing amount of hematite was observed until only hematite remained at $t=14$ hours. This suggests a sequence that progresses from an initially hydrous small particle size ferrihydrite to one of larger diameter containing less water that ultimately is consumed by conversion to hematite nanoparticles.

The same sequence emerges from our calculations at the nearest comparable temperature of $500 \mathrm{~K}$ (Fig. 3c) if one assumes that the initial ferrihydrite is comprised of a coexisting assemblage of the relatively hydrous Manceau $\left(\mathrm{Fe}_{10} \mathrm{O}_{16} \mathrm{H}_{2}\right)$ particles and relatively dry Michel $\left(\mathrm{Fe}_{10} \mathrm{O}_{16} \mathrm{H}_{2}\right)$ particles coexisting up to diameters of $2.6 \mathrm{~nm}$ (i.e., up to $t \approx 2$ hours of experimental time). Initial predominance of the Manceau particles would be consistent with the observed more hydrous initial composition, particularly Manceau particles with a slight deficiency of iron charge balanced by an excess of protons, such as by protonation of lattice $\mathrm{O}^{2-}$ sites accessible within $2 \times 1$ goethite-like channels. (Such a condition would likewise destabilize the Michel structure, as shown by Pinney et $a l^{31}$ ). Additionally, the experimental lattice parameters at $t=0$ hour, $a=5.96 \AA$ and $c=9.02 \AA$ (see Table S1 in Supplementary Materials of Ref[13]), are much closer to the DFT calculated lattice parameters we obtained for the Manceau model, $a=5.97 \AA$ and $c=9.00 \AA$, than to the calculated lattice parameters for the Michel model, $a=5.87 \AA$ and $c=9.37 \AA .{ }^{27}$ As this assemblage ages with temperature and average particle sizes increase, Manceau particles would diminish first and shift the distribution towards Michel particles (Fig. $3 \mathrm{c}$ ). The experimental observation that hematite is increasingly detected when the average ferrihydrite nanoparticles size range from $8.79 \mathrm{~nm}$ ( $t=9$ hours) to $10.96 \mathrm{~nm}$ ( $t=12$ hours) is in good agreement with our predicted maximal particle size diameter after which the Michel ferrihydrite nanoparticles become unstable with respect to hematite (>8.2 $\mathrm{nm}$ in Fig. 3c). In addition, the experimental composition analysis of ferrihydrite from $t=8$ hours to $t=12$ hours $\left(\mathrm{Fe}_{10} \mathrm{O}_{16} \mathrm{H}_{2} \cdot \mathrm{xH}_{2} \mathrm{O}\right)$ suggests that only the Michel ferrihydrite nanoparticles are present, possessing a particle size ranging from $6.80 \mathrm{~nm}$ to $10.96 \mathrm{~nm}$, in good agreement with our theoretical results.

Effect of pH on iron-oxyhydroxide solubility. In addition to temperature and water chemical potential, $\mathrm{pH}$ is also a key parameter affecting the chemical behavior of ferrihydrite such as its conversion rate to goethite and hematite. ${ }^{28,29}$ To evaluate the effect of $\mathrm{pH}$ on relative nanoparticle phase stabilities, we used the AIT calculated Gibbs free energies in combination with the Ostwald equation ${ }^{40}$ and experimental hydrolysis reaction rates ${ }^{41,42}$ to estimate equilibrium [Fe(III)] solubility for each mineral phase investigated. At $\mathrm{T}=298.15 \mathrm{~K}, \mathrm{pH}_{2} \mathrm{O}=32 \mathrm{mbar}$ and $\mathrm{pH}=7$, Figure 4a shows that the relative stability of the various phases in terms of solubilities is similar to those observed in Figure $3 \mathrm{~b}$ across a wide $\mathrm{pH}$ 
range. In contrast to the particle-size effect, which depends primarily on different $\left(\mathrm{T}, p \mathrm{H}_{2} \mathrm{O}\right)$ conditions, the main effect of $\mathrm{pH}$ is to shift the equilibrium [Fe(III)] solubility toward either higher or lower values for all phases (Fig. $4 \mathrm{~b}$ and S4). Figure $4 \mathrm{~b}$ shows an asymmetric $\mathrm{pH}$-dependent solubility which is lowest at $\mathrm{pH}=8$ for each mineral phase. Importantly, in terms of relative [Fe(III)] solubilities the findings predict an order of appearance (e.g., from saturated aqueous solution) analogous to an Ostwald-Lussac law of phases of lepidocrocite $\rightarrow$ orthorhombic phase $\rightarrow$ Michel Fh $\rightarrow$ Manceau Fh $\rightarrow$ goethite $\rightarrow$ hematite. The close [Fe(III)] solubilities predicted for the two ferrihydrite models of Michel and Manceau resembles the same close relationship between hematite and goethite.
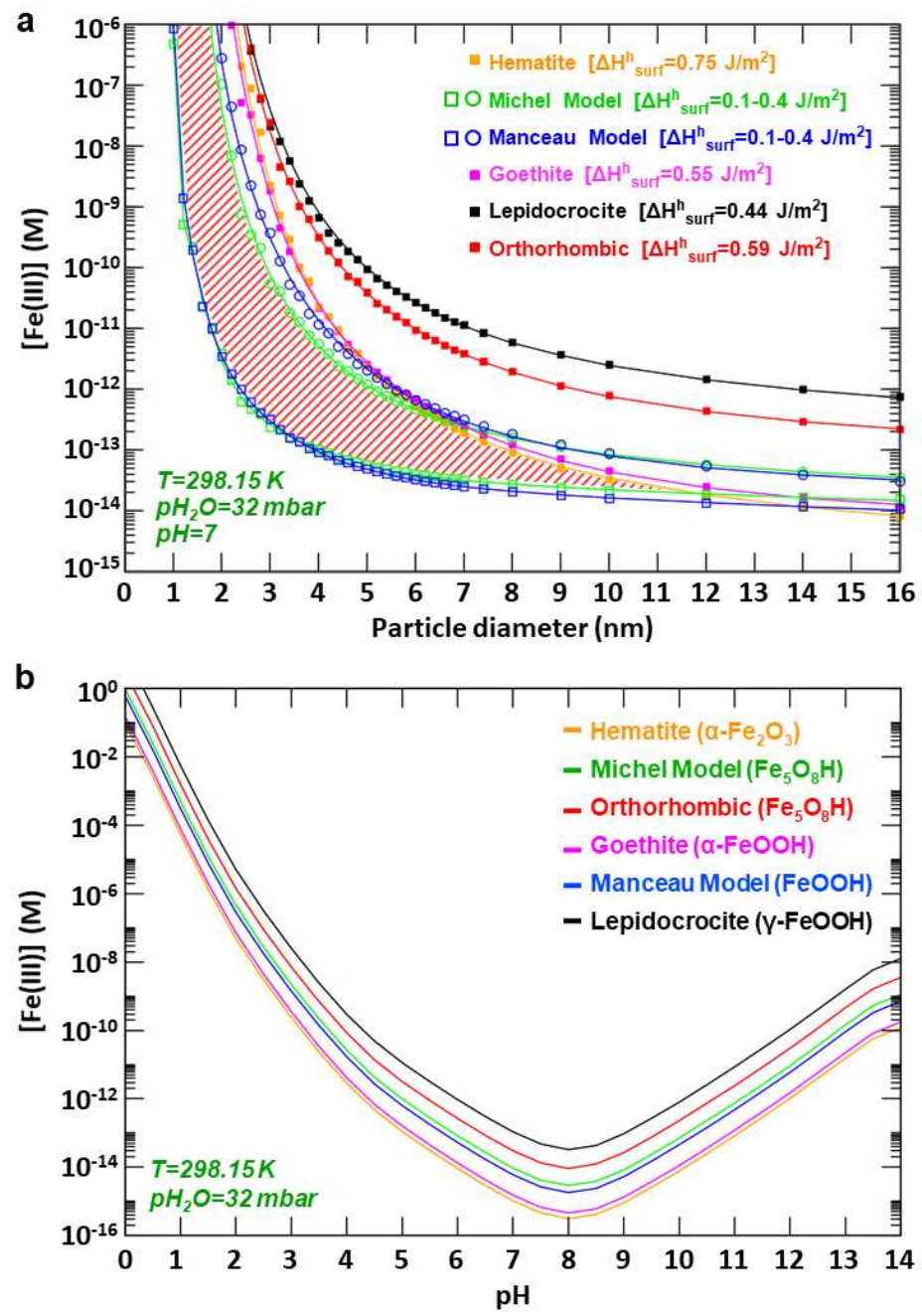

Figure 4: Solubility of iron-oxyhydroxide phases. Equilibrium solubility of [Fe(III)] for the various minerals in pure water. (a) Particle-size dependence of [Fe(III)] solubility at $\mathrm{pH}=7$. The red hatched area represents the size-range of particles for which the two ferrihydrite models can potentially coexist. (b) $\mathrm{pH}$-dependence of [Fe(III)] solubility of iron (oxyhydr)oxide phases considered as virtual bulk lattices.

\section{Conclusions:}

DFT-based ab initio thermodynamics calculations comparing the stabilities of two prominent single-phase structure models of ferrihydrite in aqueous environments indicate overlapping phase fields and their likely coexistence at the nanoscale. The finding suggests that phases known as 2-line 
and 6-line ferrihydrites may actually be comprised of an assemblage of distinct particle types not readily distinguishable by X-ray diffraction or scattering techniques.

In terms of virtual bulk lattices, analysis of the relative phase stability indicates that the Manceau model is stable for temperatures below $295 \mathrm{~K}$ with respect to hematite and is the preferred ferrihydrite phase at standard temperature and pressure (i.e., $\mathrm{T}=298.15 \mathrm{~K}$ and $p \mathrm{H}_{2} \mathrm{O}=1$ bar) compared to the Michel model. The Manceau model corresponds to a wet ferrihydrite phase. In contrast, the Michel model is stable at temperatures above $360 \mathrm{~K}$ and can be considered the most suitable model for a dry phase of ferrihydrite. A hypothetical orthorhombic phase was found to be only $0.3 \mathrm{~kJ} / \mathrm{mol}$-Fe less favorable than lepidocrocite at standard temperature and pressure, representing a possible transition phase to goethite that is competitive with lepidocrocite. The predicted best temperature range to stabilize this orthorhombic structure is between $303 \mathrm{~K}$ and $340 \mathrm{~K}$, which is just after the lepidocrocite/orthorhombic phase transition and just before the goethite/hematite phase transition.

Calculation of particle size dependent ab initio thermodynamics indicates that the Manceau and Michel single-phase ferrihydrite nanoparticles can be expected to generally coexist for small particle diameters at least up to approximately $3 \mathrm{~nm}$ over a large working range of temperature and partial pressure of water. The main effect of temperature and water pressure is to shift the distribution of ferrihydrite particle types via differences in their stable particle sizes, and also to determine the most stable crystalline end-product phase into which they transform. Higher temperature and/or higher water pressure favor the formation of Michel ferrihydrite nanoparticles and hematite, while lower temperature and/or lower water pressure favor formation of Manceau ferrihydrite nanoparticles and goethite. We found that at the routine experimental conditions of $298.15 \mathrm{~K}$ and $p \mathrm{H}_{2} \mathrm{O}=1$ bar both wet and dry single-phase ferrihydrite particle types can be expected to coexist up to about $8 \mathrm{~nm}$ in particle diameter. 


\section{Methods}

Density functional theory simulations. Ab initio total energy calculations and geometry optimizations were performed using the VASP package. ${ }^{43,44}$ All of the calculations used the generalized gradient approximation (GGA), as parametrized by Perdew, Burke and Ernzerhof (PBE), ${ }^{45}$ to describe the exchange-correlation functional. The cutoff energy of the projector augmented wave ${ }^{46}$ pseudopotentials were all fixed to $800 \mathrm{eV}$. In each case, the total energy was converged to $10^{-8} \mathrm{eV} /$ cell and the force components were relaxed to $10^{-5} \mathrm{eV} / \AA$. A Monkhorst-Pack scheme $k$-points mesh of $6 \times 6 \times 4$ was used for the sampling of the Brillouin zone. In order to correctly describe the magnetic ordering of the ground state of the six iron-oxide phases of interest, each calculation used spin-polarization along with the Vosko-Wilk-Nusair scheme. ${ }^{47}$ Additionally, the GGA+U method, as described by Dudarev, ${ }^{48}$ was used for the Fe atoms to correct the poor description of the Coulomb repulsion of the $3 \mathrm{~d}$ electrons ${ }^{49}$ in standard GGA. The Hubbard parameter $U$, describing the Coulomb interaction, was fixed to $4 \mathrm{eV}$, while the screened exchange energy, $J$, was fixed to $1 \mathrm{eV}\left(U_{\text {eff }}=U-J=3 \mathrm{eV}\right)$. In order to account for the atomization errors induced by $\mathrm{GGA}$ for $\mathrm{H}_{2} \mathrm{O}, \mathrm{H}_{2}, \mathrm{O}_{2}$, and Fe the total energies of these species have been corrected by using their experimental, zero point energy corrected, atomization energies. ${ }^{45,50}$ Therefore, the total energy of $\mathrm{H}_{2} \mathrm{O}, \mathrm{H}_{2}, \mathrm{O}_{2}$ molecules, and Fe bulk were respectively corrected by 0.029 $\mathrm{eV},-0.192 \mathrm{eV}, 0.805 \mathrm{eV}$, and $-0.495 \mathrm{eV}$. A visual representation of the phases investigated is shown in Figure S1 in Supplementary Materials.

Phonon dispersion relationship. The phonon dispersion relationship was computed for each mineral phase by using a direct approach to the lattice dynamics, as implemented in the phonopy code. ${ }^{51}$ The vibrational frequencies, obtained at the $\Gamma$-point, were subsequently used to calculate the zero-point energy of each phase as well as the temperature dependent vibrational entropy contribution. These two quantities were used to calculate AIT quantities of periodic bulk and nanoparticles.

Hydroxylated surface enthalpy and entropy. Including the effect of particle size in the AIT calculations required evaluation of the surface entropy and enthalpy contributions. The surface enthalpy contributions for goethite, hematite, lepidocrocite, and the orthorhombic phase, were treated explicitly, using classical force field methods as implemented in the Metadise code. ${ }^{52}$ For each of these mineral phases, at least seven surface directions were investigated and the calculation of hydroxylated surface enthalpy was determined as described by de Leeuw et al., ${ }^{53}$ which uses a calculated water dissociation energy. The force field for each specie used in these classical simulations were the same as those listed in that study. ${ }^{53}$ The lowest hydroxylated surface enthalpy calculated for each surface direction was used to build the Wulff construction for each mineral phase, representing the equilibrium crystal morphology for hydroxylated surfaces, by using the Wulffman program. ${ }^{54}$ From the Wulff construction, we determined a weighted averaged hydroxylated surface enthalpy, $\Delta \mathrm{H}^{\mathrm{h}}$ surf. The Wullf representation and surface enthalpy details for each phase can be found in Figure S2 in the Supplementary Materials.

Nanoparticle thermodynamic model. For the two ferrihydrite models, goethite, hematite, lepidocrocite, and the orthorhombic phases, the determination of the surface entropy contributions 
was performed as described in the thermodynamical framework of Hiesmtra. ${ }^{35}$ For goethite, hematite, lepidocrocite and the Michel ferrihydrite model, contributions similar to those of Hiemstra ${ }^{35}$ were obtained for the surface entropy. The details of each contribution to the surface entropy can be found in Table S1 and S2 in the Supplementary Materials. The calculation of pH-dependent [Fe(III)] solubilities for each mineral phase followed the methodology outlined by Hiemstra, ${ }^{35}$ Liu, $^{41}$ and Millero. ${ }^{42}$ Additional details on the calculation of the solubilities are provided in Supplementary Materials. 


\section{Author Information:}

Corresponding Author

*E-mail: michel.sassi@pnnl.gov

\section{ORCID:}

Michel Sassi: 0000-0003-2582-3735

Anne M. Chaka: 0000-0001-7872-7590

Kevin M. Rosso: 0000-0002-8474-7720

\section{Acknowledgements:}

This research is based upon work supported by the U.S. Department of Energy, Office of Science, Office of Basic Energy Sciences, Chemical Sciences, Geosciences, and Biosciences Division through its Geosciences program at Pacific Northwest National Laboratory (PNNL). PNNL is a multi-program national laboratory operated for the DOE by Battelle Memorial Institute under Contract No. DE-ACO576RL01830. Computational resources were provided by PNNL Institutional Computing (PIC).

\section{Author contributions:}

M. S. conceived the idea. M. S. and A. M. C. performed the DFT and ab initio thermodynamic calculations. All authors interpreted the results, drafted, reviewed, and revised the manuscript.

\section{Competing interests:}

The authors declare no competing financial interest. 


\section{References:}

1. Cornell, R. M.; Schwertmann, U., The iron oxides: Structure, properties, reactions, occurrences and uses. 2nd ed. ed.; Wiley-VCH: Weinheim; Cambridge, (2003).

2. Jenssen, S.; Larsen, F.; Koch, C. B.; Arvin, E. Sorption and desorption of arsenic to ferrihydrite in a sand filter. Environmental Science and Technology 39, 8045-8051 (2005).

3. Hodge, N. A.; Kiely, C. J.; Whyman, R.; Siddiqui, M. R. H.; Hutchings, G. J.; Pankhurst, Q. A.; Wagner, F. E.; Rajaram, R. R.; Golinski, S. E. Microsctructural comparison of calcined and uncalcined gold/iron-oxide catalysts for low-temperature CO oxidation. Catalysis Today 72, 133-144 (2002).

4. Childs, C. W. Ferrihydrite: A review of structure, properties and occurrence in relation to soils. $Z$. Pflanzenernahr. Bodenk 155, 441-448 (1992).

5. Carlson, L.; Schwertmann, U. Natural ferrihydrites in surface deposits from Finland and their association with silica. Geochim. Cosmochim. Acta 45, 421-429 (1981).

6. Michel, F. M.; Ehm, L.; Liu, G.; Han, W. Q.; Antao, S. M.; Chupas, P. J.; Lee, P. L.; Knorr, K.; Eulert, H.; Kim, J.; Grey, C. P.; Celestian, A. J.; Gillow, J.; Schoonen, M. A. A.; Strongin, D. R.; Parise, J. B. Similarities in 2- and 6-line ferrihydrite based on pair distribution function analysis of X-ray total scattering. Chemistry of Materials 19, 1489-1496 (2007).

7. Schwertmann, U.; Friedl, J.; Kyek, A. Formation and properties of a continuous crystallinity series of synthetic ferrihydrite (2- to 6-line) and their relation to FeOOH forms. Clays and Clay Minerals 52, 221-226 (2004).

8. Berquo, T. S.; Banerjee, S. K.; Ford, R. G.; Penn, R. L.; Pichler, T. High crystallinity Si-ferrihydrite: An insight into its Néel temperature and size dependence of magnetic properties. Journal of Geophysical Research 112, B02102 (2007).

9. Wang, X.; Zhu, M.; Koopal, L. K.; Li, W.; Xu, W.; Liu, F.; Zhang, J.; Liu, Q.; Feng, X.; Sparks, D. L. Effects Of Crystallite Size On The Structure And Magnetism Of Ferrihydrite. Environmental Science Nano 3, 190-202 (2016).

10. Chappell, H. F.; Thom, W.; Bowron, D. T.; Faria, N.; Hasnip, P. J.; Powell, J. J. Structure of naturally hydrated ferrihydrite revealed through neutron diffraction and first-principles modeling. Physical Review Materials 1, 036002 (2017).

11. Liu, H.; Li, X.; Wang, Y.; Yang, X.; Zhen, Z.; Chen, R.; Hu, D.; Wei, Y. New insight into the effect of the formation environment of ferrihydrite on its structure and properties. RSC Advances 4, 11451 (2014).

12. Hochella, M. F.; Lower, S. K.; Maurice, P. A.; Penn, R. L.; Sahai, N.; Sparks, D. L.; Twining, B. S. Nanominerals, mineral nanoparticles, and Earth systems. Science 319, 1631-1635 (2008).

13. Michel, F. M.; Barron, V.; Torrent, J.; Morales, M. P.; Serna, C. J.; Boily, J. F.; Liu, Q. S.; Ambrosini, A.; Cismasu, A. C.; Brown, G. E., Ordered ferrimagnetic form of ferrihydrite reveals links among structure, composition, and magnetism. Proceedings of the National Academy of Sciences of the United States of America 107, 2787-2792 (2010).

14. Navrotsky, A.; Mazeina, L.; Majzlan, J. Size-driven structural and thermodynamic complexity in iron oxides. Science 319, 1635-1638 (2008). 
15. Michel, F. M.; Ehm, L.; Antao, S. M.; Lee, P. L.; Chupas, P. J.; Liu, G.; Strongin, D. R.; Schoonen, M. A. A.; Phillips, B. L.; Parise, J. B. The structure of ferrihydrite, a nanocrystalline material. Science 316, 1726-1729 (2007).

16. Manceau, A.; Skanthakumar, S.; Soderholm, L. PDF analysis of ferrihydrite: Critical assessment of the under-constrained akdalaite model. American Mineralogist 99, 102-108 (2014).

17. Towe, K. M.; Bradley, W. F. Mineralogical constitution of colloidal hydrous ferric oxides. Journal of Colloid Interface Science 24, 384 (1967).

18. Eggleton, R. A.; Fitzpatrick, R. W., New data and a revised structural model for ferrihydrite. Clays and Clay Minerals 36, 111-124 (1988).

19. Jambor, J. L.; Dutrizac, J. E., Occurrence and constitution of natural and synthetic ferrihydrite, a widespread iron oxyhydroxide. Chemical Reviews 98, 2549-2585 (1998).

20. Drits, V. A.; Sakharov, B. A.; Salyn, A. L.; Manceau, A., Structural model for ferrihydrite. Clay Minerals 28, 185-207 (1993).

21. Funnell, N. P.; Fulford, M. F.; Inoué, S.; Kletetschka, K.; Michel, F. M.; Goodwin, A. L. Nanocomposite structure of two-line ferrihydrite powder from total scattering. Communication Chemistry 22, 1 (2020).

22. Rancourt, D. G.; Meunier, J. F., Constraints on structural models of ferrihydrite as a nanocrystalline material. American Mineralogist 93, 1412-1417 (2008).

23. Manceau, A., Evaluation of the structural model for ferrihydrite derived from real-space modelling of high-energy X-ray diffraction data. Clay Minerals 44, 19-34 (2009).

24. Jansen, E.; Kyek, A.; Schäfer, W.; Schwertmann, U. The structure of six-line ferrihydrite. Applied Physics A 74, S1004-S1006 (2002).

25. Gilbert, B.; Erbs, J. J.; Penn, R. L.; Petkov, V.; Spagnoli, D.; Waychunas, G. A. A disordered nanoparticle model for 6-line ferrihydrite. American Mineralogist 98, 1465-1476 (2013).

26. Hiemstra, T. Surface structure controlling nanoparticle behavior: magnetism of ferrihydrite, magnetite, and maghemite. Environmental Science: Nano 5, 752 (2018).

27. Sassi, M.; Rosso, K. M. Roles of Hydration and Magnetism on the Structure of Ferrihydrite from First Principles. ACS Earth and Space Chemistry 3, 70-78 (2018).

28. Schwertmann, U.; Murad, E. Effect of $\mathrm{pH}$ on the formation of goethite and hematite from ferrihydrite. Clays and Clay Minerals 31, 277-284 (1983).

29. Cornell, R. M.; Giovanoli, R.; Schneider, W. Review of the hydrolysis of iron(III) and the crystallization of amorphous iron(III) hydroxide hydrate. Journal of Chemical Technology and Biotechnology 46, 115-134 (1989).

30. Pinney, N.; Kubicki, J. D.; Middlemiss, D. S.; Grey, C. P.; Morgan, D. Density functional theory study of ferrihydrite and related Fe-oxyhydroxides. Chemistry of Materials 21, 5727-5742 (2009).

31. Pinney, N.; Morgan, D. Ab initio study of structurally bound water at cation vacancy sites in Fe- and Al-oxyhydroxide materials. Geochimica Et Cosmochimica Acta 114, 94-111 (2013). 
32. Hiemstra, T.; Van Riemsdijk, W. H., A surface structural model for ferrihydrite I: Sites related to primary charge, molar mass, and mass density. Geochimica Et Cosmochimica Acta 73, 4423-4436 (2009).

33. Hiemstra, T.; Van Riemsdijk, W. H.; Rossberg, A.; Ulrich, K. U., A surface structural model for ferrihydrite II: Adsorption of uranyl and carbonate. Geochimica Et Cosmochimica Acta 73, 44374451 (2009).

34. Hiemstra, T. Surface and mineral structure of ferrihydrite. Geochimica Et Cosmochimica Acta 105, 316-325 (2013).

35. Hiemstra, T. Formation, stability, and solubility of metal oxide nanoparticles: Surface entropy, enthalpy, and free energy of ferrihydrite. Geochimica Et Cosmochimica Acta 158, 179-198 (2015).

36. Boily, J.-F.; Song, X. Direct identification of reaction sites on ferrihydrite. Communication Chemistry 3, 79 (2020).

37. Chaka, A. M.; Felmy, A. R. Ab Initio Thermodynamic Model for Magnesium Carbonates and Hydrates. Journal of Physical Chemistry A 118, 7469-7488 (2014).

38. NIST-JANAF Thermochemical Tables, 4th ed., edited by J. M. W. Chase American Chemical Society, Washington, DC, 1998.

39. Majzlan, J.; Navrotsky, A.; Schwertmann, U. Thermodynamics of iron oxides: Part III. Enthalpies of formation and stability of ferrihydrite (similar to $\mathrm{Fe}(\mathrm{OH})_{3}$ ), schwertmannite (similar to $\left.\mathrm{FeO}(\mathrm{OH})_{3 / 4}(\mathrm{SO})_{1 / 8}\right)$, and epsilon- $\mathrm{Fe}_{2} \mathrm{O}_{3}$. Geochimica Et Cosmochimica Acta 68, 1049-1059 (2004).

40. Ostwald, W. Über die vermeintliche Isomerie des roten und gelben Quecksilberoxyds und die Oberflächenspannung fester Körper. Z. Für Phys. Chem. 34, 495-503 (1900).

41. Liu, X.; Millero, F. J. The solubility of iron hydroxide in sodium chloride solutions. Geochimica Et Cosmochimica Acta 63, 3487-3497 (1999).

42. Millero, F. J; Yao, W.; Aicher, J. The separation of Fe(II) and Fe(III) in natural waters. Marine Chemistry 50, 21-39 (1995).

43. Kresse, G.; Furthmuller, J. Efficient iterative schemes for ab initio total-energy calculations using a plane-wave basis set. Physical Review B 54, 11169-11186 (1996).

44. Kresse, G.; Furthmuller, J. Efficiency of ab-initio total energy calculations for metals and semiconductors using a plane-wave basis set. Computational Materials Science 6, 15-50 (1996).

45. Perdew, J. P.; Burke, K.; Ernzerhof, M. Generalized gradient approximation made simple. Physical Review Letters 77, 3865-3868 (1996).

46. Blochl, P. E. Projector augmented-wave method. Physical Review B 50, 17953-17979 (1994).

47. Vosko, S. H.; Wilk, L.; Nusair, M. Accurate spin-dependent electron liquid correlation energies for local spin density calculations: A critical analysis. Canadian Journal of Physics 58, 1200-1211 (1980).

48. Dudarev, S. L.; Botton, G. A.; Savrasov, S. Y.; Szotek, Z.; Temmerman, W. M.; Sutton, A. P. Electronic structure and elastic properties of strongly correlated metal oxides from first principles: LSDA+U, SIC-LSDA and EELS study of UO2 and NiO. Physica Status Solidi A: Applications and Materials Science 166, 429-443 (1998). 
49. Anisimov, V. I.; Aryasetiawan, F.; Lichtenstein, A. I. First-principles calculations of the electronic structure and spectra of strongly correlated systems: The LDA+U method. Journal of PhysicsCondensed Matter 9, 767-808 (1997).

50. Janthon, P.; Luo, S.; Kozlov, S. M.; Viñes, F.; Limtrakul, J.; Truhlar, D. G.; Illas, F. Bulk Properties of transition metals: A challenge for the design of universal density functionals. Journal of Chemical Theory and Computation 10, 3832-3839 (2014).

51. Togo, A.; Tanaka, I. First principles phonon calculations in materials science. Scripta Materialia 108, 1-5 (2015).

52. Watson, G. W.; Kelsey, E. T.; de Leeuw, N. H.; Harris, D. J.; Parker, S. C. Atomistic simulation of dislocations, surfaces and interfaces in MgO. Journal of the Chemical Society-Faraday Transactions 92, 433-438 (1996).

53. de Leeuw, N. H.; Cooper, T. G. Surface simulation studies of the hydration of white rust $\mathrm{Fe}(\mathrm{OH})_{2}$, goethite alpha- $\mathrm{FeO}(\mathrm{OH})$ and hematite alpha- $\mathrm{Fe}_{2} \mathrm{O}_{3}$. Geochimica Et Cosmochimica Acta 71, 16551673 (2007).

54. Roosen, A. R.; McCormack, R. P.; Carter, W. C. Wulffman: A tool for the calculation and display of crystal shapes. Computational Materials Science 11, 16-26 (1998). 
Figures

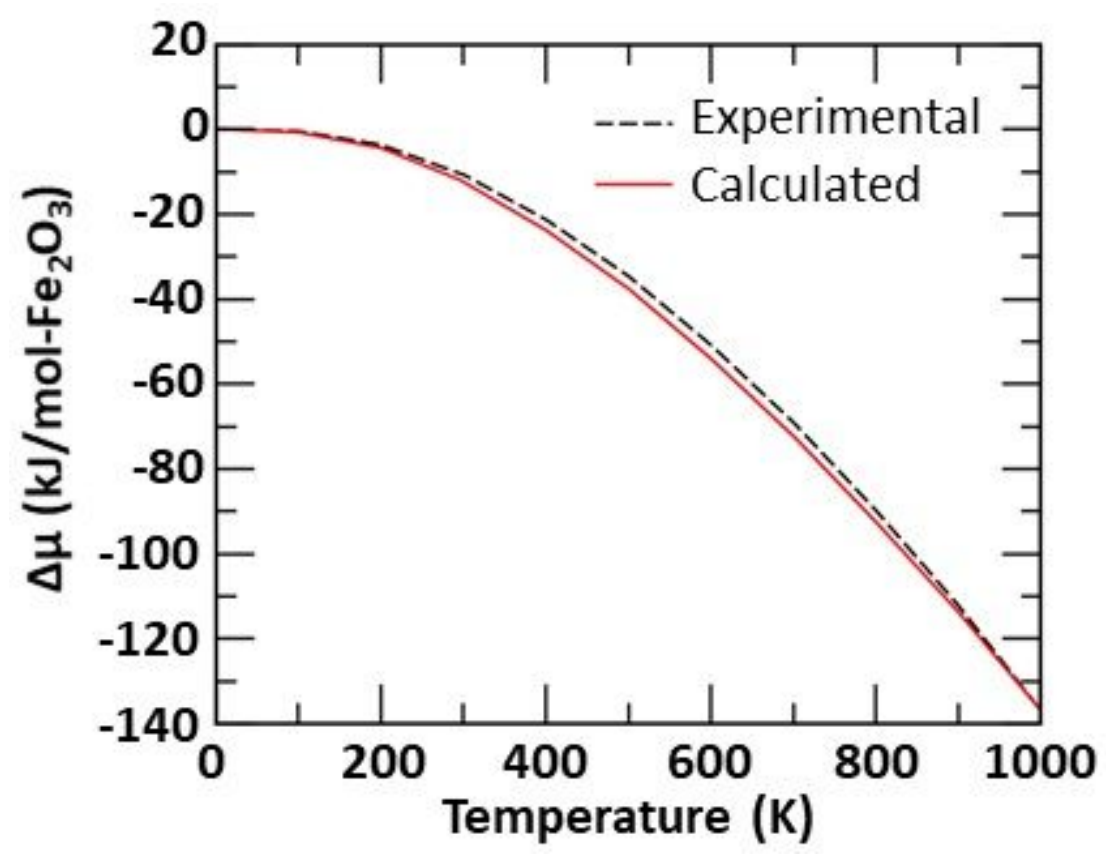

Figure 1

Evolution of the chemical potential with temperature. Comparison between DFT+U calculated and experimental JANAF values of $\Delta \mu(\mathrm{T}, \mathrm{P})$ (in $\mathrm{kJ} / \mathrm{mol}-\mathrm{Fe} 2 \mathrm{O} 3$ ) for hematite (a-Fe203) at $\mathrm{P}=1$ bar. 

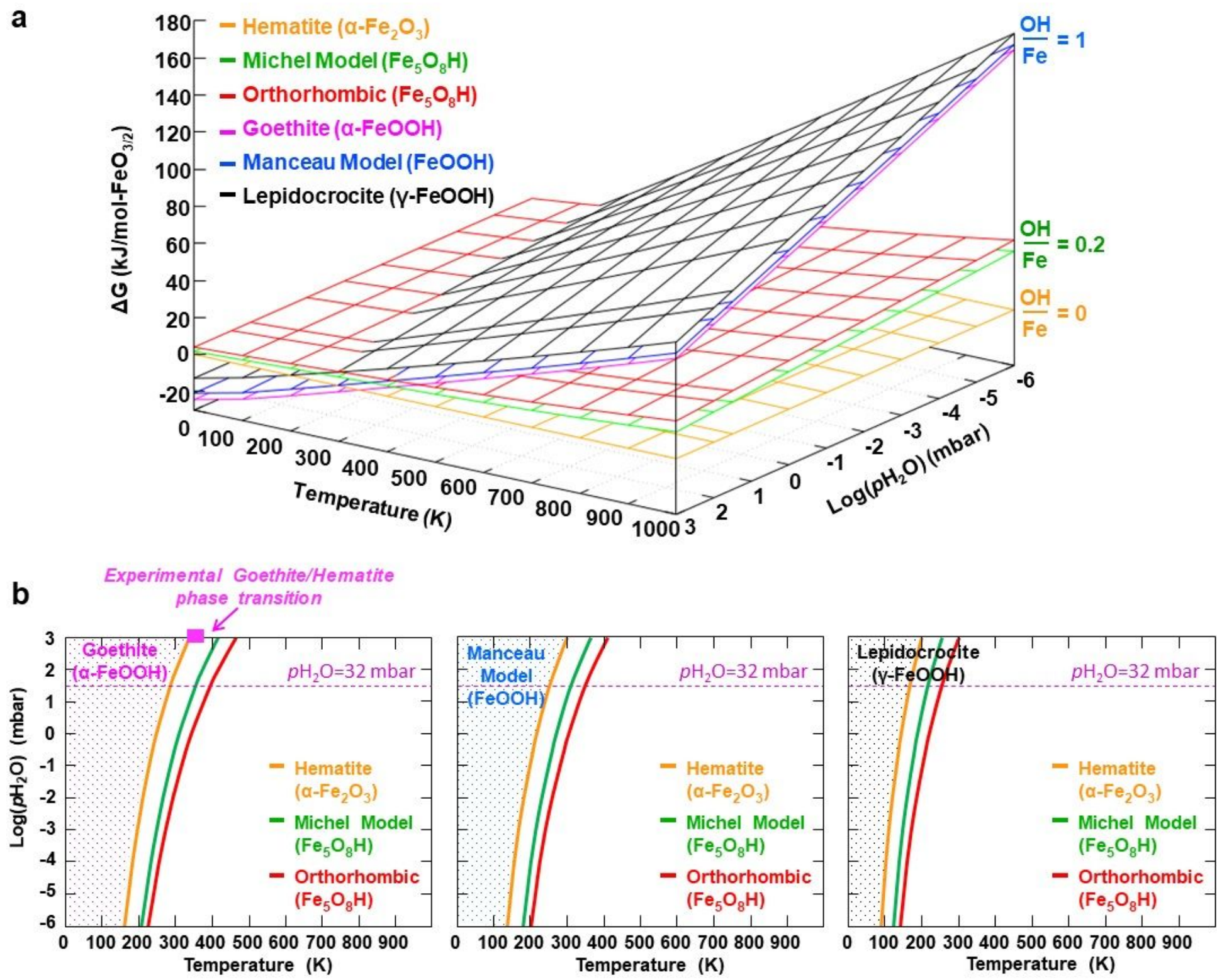

Figure 2

Relative phase stability of mineral phases. Calculated relative bulk phase stabilities for hematite, goethite, lepidocrocite, the two ferrihydrite models and the orthorhombic structure. a) 3D plot of the Gibbs free energy as function of the temperature and water partial pressure. b) Water pressure-temperature phase diagrams showing the domain of stability for each phase and the conditions at various phase boundaries. The purple dashed line indicates the water pressure for which $\mathrm{pH} 2 \mathrm{O}=32 \mathrm{mbar}$. The color dotted areas highlight the $(\mathrm{T}, \mathrm{P})$ conditions at which each $\mathrm{FeOOH}$ phase is the most thermodynamically favorable. 

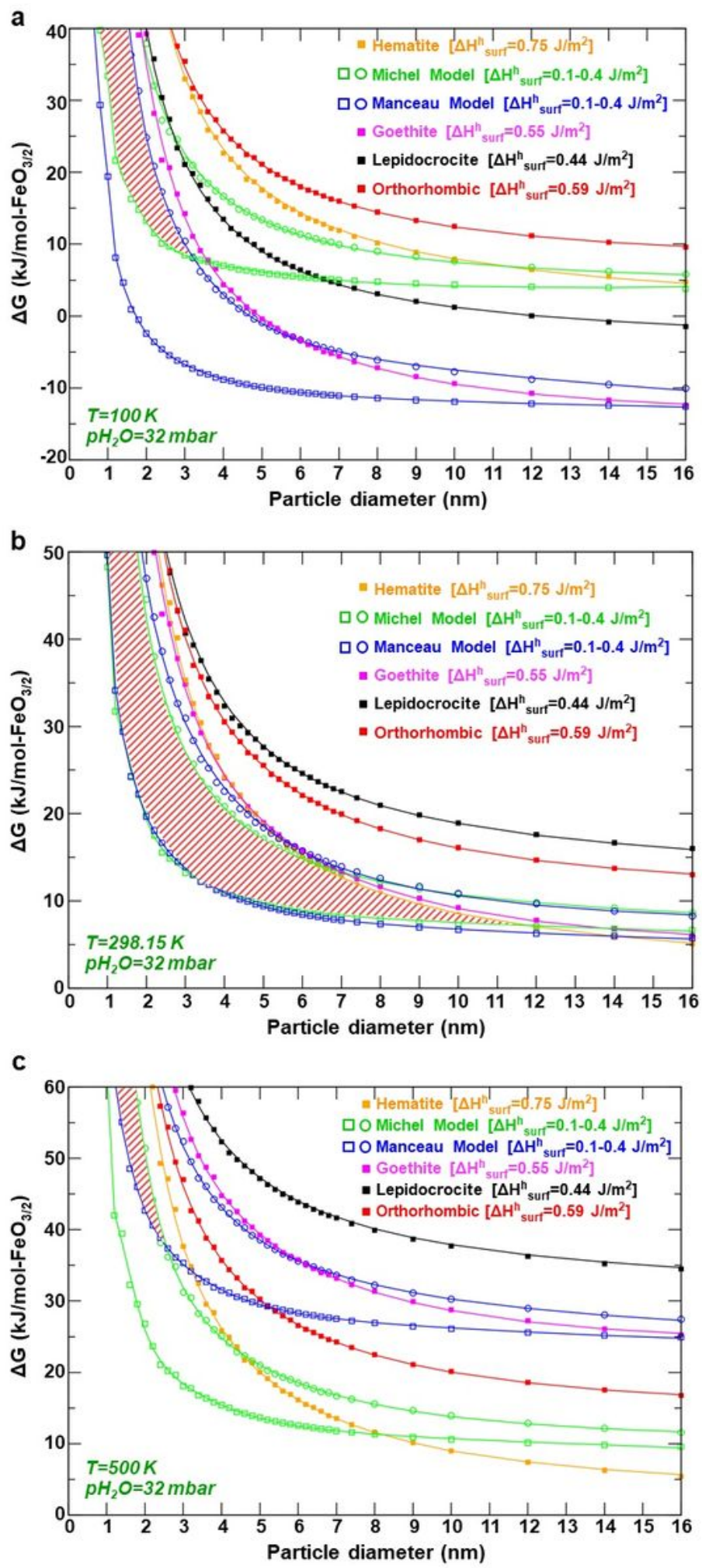

\section{Figure 3}

Coexistence of structurally different Fh nanoparticles. Particle-size dependency of the relative phase stability of the Manceau and Michel ferrihydrite models as well as for goethite, lepidocrocite, hematite and the orthorhombic phase for $\mathrm{pH} 2 \mathrm{O}=32 \mathrm{mbar}$ and (a) $\mathrm{T}=100 \mathrm{~K}$, (b) $\mathrm{T}=298.15 \mathrm{~K}$, and (c) $\mathrm{T}=500 \mathrm{~K}$. For the two ferrihydrite models, the curves with open squares were obtained using $\Delta$ Hhsurf $=0.1 \mathrm{~J} / \mathrm{m} 2$, while the curves with open circles used $\Delta \mathrm{Hhsurf}=0.4 \mathrm{~J} / \mathrm{m} 2$. Square filled curves used $\Delta$ Hhsurf calculated for 
hydroxylated periodic surface crystals. The red hatched area represents the size-range of particles for which the two ferrihydrite models can potentially coexist.
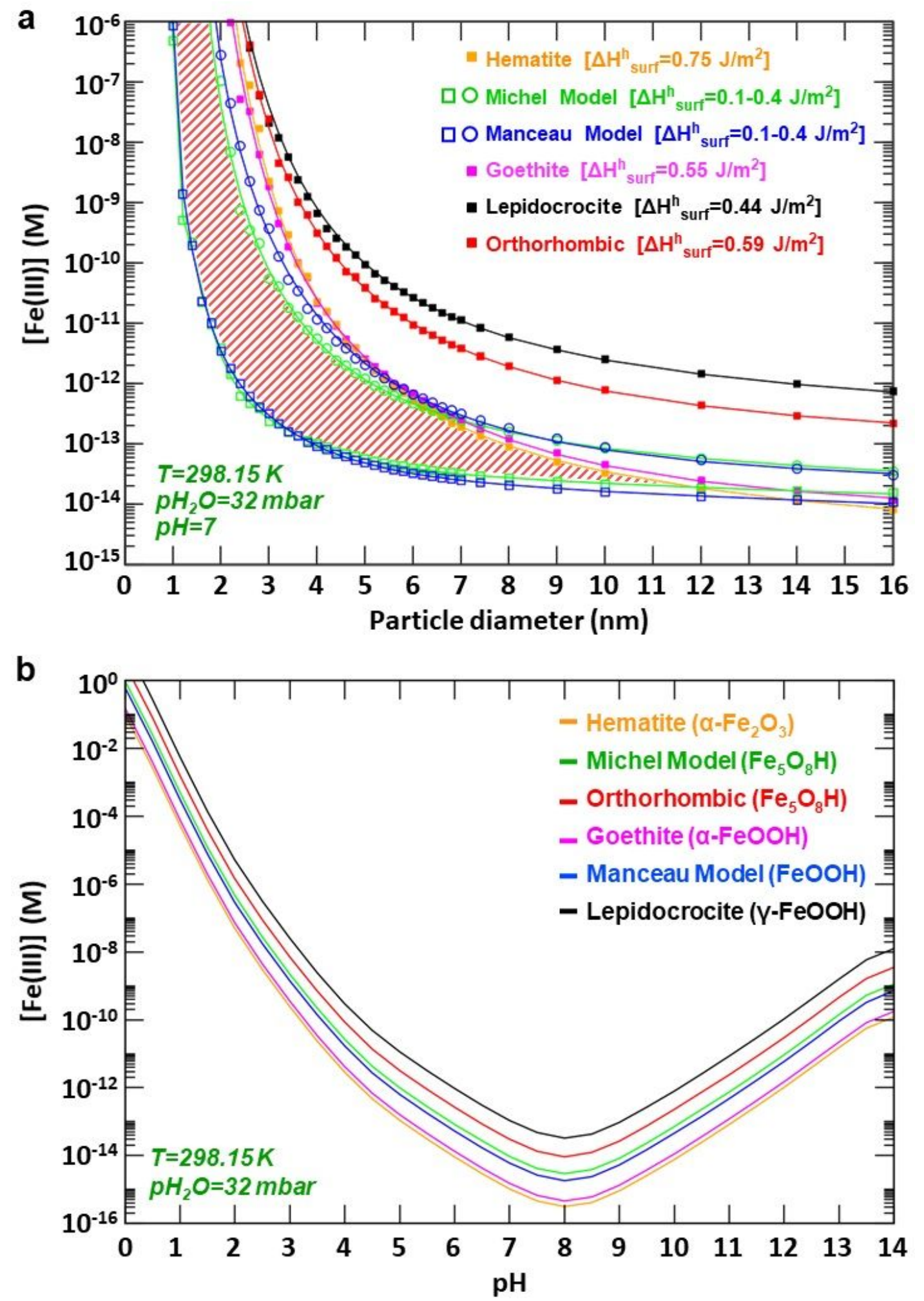

Figure 4

Solubility of iron-oxyhydroxide phases. Equilibrium solubility of $[\mathrm{Fe}(\mathrm{III})]$ for the various minerals in pure water. (a) Particle-size dependence of [Fe(III)] solubility at $\mathrm{pH}=7$. The red hatched area represents the size- 
range of particles for which the two ferrihydrite models can potentially coexist. (b) pH-dependence of [Fe(III)] solubility of iron (oxyhydr)oxide phases considered as virtual bulk lattices.

\section{Supplementary Files}

This is a list of supplementary files associated with this preprint. Click to download.

- SassietalCommunChemSI.pdf 